\title{
A Functional Analysis of the Changed Business Role of the Postmodernist Fash- ion Design Studio in Contemporary China
}

\author{
Wang Jun ${ }^{1}$ Gail Taylor ${ }^{2}$ Jiang Shou-xiang ${ }^{2}$ \\ ${ }^{1}$ Dong Hua University, China \\ ${ }^{2}$ The Hong Kong Polytechnic University, Institute of Textiles and Clothing, China
}

\begin{abstract}
This investigation was conducted within the context of the practice of postmodernist fashion in China, and in particular the development of the fashion design studio. It was found that the practice consisted of five types of subject matter, including the material content of design studio, the craft which constituted the essence of design, the artisan who established the aesthetic value of fashion, the tool which developed the reliable solution, and the environment in which the business developed. The output of the design studio, which was constructed on the bases of these factors, evolved in accordance with the development of China.
\end{abstract}

Keywords: postmodernist, fashion, design, studio business, China

\section{Instruction}

The aim of this investigation was to analyze the factors which constituted the business of a design studio in China, including traditional concepts, evolving forms, and primary components of design, from the perspective of postmodernist fashion, which comprised of characteristics, meanings and expressions of the postmodernist fashion, and make a fun- damental analysis of this practiceassociated subject.

Based on the investigation of the practice of design in ancient China, Khao Kung Chi (Needham, 1956) reported five types of conceptual issues of relevance to design. The nature of these five issues evolved within different contexts (Ledderose, 2000). The design was associated with the characteristics of materials; on the other hand, design was a means of expressing internal ideas (Brown and Wyatt, 2010). Wang, et al, (2012) observed the existent form of design from the perspective of practice. The prior investigations of the postmodernist fashion generally identified two different types of approaches to their enquires. One type (Bourdieu, 1974; Barthes, 1985; Roche, 1994; Paulicelli, 2004) placed their emphases on the form of existence, which was associated with the development of a system; the other type (Wu, 2009; Tsui, 2009, Montgomery, 2010) targeted the clarification of the relationship within the system. These two types of attributes constituted the integral characteristics of the postmodernist fashion.

\section{Development of business}

Developing the cutting edge of a complex subject such as fashion spurred the development of independent design studios in 
China. The researching, evolving and developing (RED) constituted three stages of a business. The reliability of the RED was associated with three types of influential factors. At the stage of conceptual research, the unit of control was associated with the time of developing a circle inclusive of the initial survey and organized schedule. During the process of developing products, the content of management was associated with the cost of the productive investment, including the payment of the participant and the consumption of materials. The functions, which consisted of the quantity and quality of design, constructed the foundation of the business.

The evolution of the RED consisted of three types of components, these being the innovative ideas of the freelancer, who was able to identify the distinct concept from the mass, the professional knowledge of experts, which established the basic instruction for the associated practice, and the collected documents of the production, which recorded the realisation of products.

Within the cultural context of China, five types of the concepts, which were associated with the expressed form of the postmodernist fashion, were derived from the RED

\section{New item}

With the development of industry, more and more materials became available for designers to use; the characteristic of new materials, which were different from those of the traditional fabrics, developed a new understanding of design in turn, and changed the way in which fashion was designed. The physical attributes of design, which were derived from technological developments such as new embroidery techniques, revealed the symbolic meanings of fashion, which were associated with the cultural concepts such as
Taoism, constituted the basic objectives for the design studio.

\section{New craft}

Being confronted with the challenge accompanied by innovations in fashion knowledge and design materials, the establishment of a valid way, which was capable of clarifying the connotations of fashion, became essential in the business of design. Together with the existing approaches such as decomposing, mixing, matching and assembling, which were essentially mechanical, the identification of primary components of fashion design, such as "ta-ch' $i$ ", which were associated with the inner world of a person, constituted the essential field of the design studio.

\section{New artisan}

Within the range of the design studio, when compared with the practitioner performing tasks such as inputting and outputting narrative data of clothing parts, which were a part of the integrated system of fashion, the designer with unique characters, who played an essential role in the practical development of business, were active in the fundamental work, developed fashion prototypes by means of observing, categorising and applying the intensive information for a design, derived from their aesthetic values.

\section{New tool}

Today technological advances have enabled the processing of parameters, associated with expressed attributes and recorded by means of physical and psychological descriptions, such as 3D scanning to obtain accurate measurements for underwear and the measurement of brain waves to determine levels of comfort for sportswear. The solution to the upgrading 
of fashion quality at an advanced level, for example, in the case of luxury items which enhance the moods of consumers, can be found when codes acquired from metaphysical analysis are formulated. The analytical accuracy of the complex subject is necessarily limited within the confines of the specific space in which it exists.

\section{New world}

The established fashion studios have bridged the gap between the development of a style prototype and the garment manufacturer involved in, for example the mass production of clothing. The characteristics of their forms were diverse and multifold. The coordination of their business was constituted by two types of units. There were the control of time for the transformation process to take place, inclusive of available resources, which features the fashion styles should have, and the given schedule for the design process; subsequently the management of cost which entailed balancing the budget between the investment in the infrastructure for sourcing and sampling and the payment of the research and development team with the knowledge of the specific culture. The primary unit of the coordination, which was derived from the concept of nothingness, revealed the nature of the space and indicated the potential direction for the development of the business.

\section{Discussion}

In the light of the previous discussion, it can be seen that the development of the design studio comprised of three main activities, these being the research of innovative ideas, the evolution of professional knowledge, and the generation of production documents, all of which contributed to the interrelated structure of business. A wheel diagram was designed to illuminate the span of RED (Figure 1)..

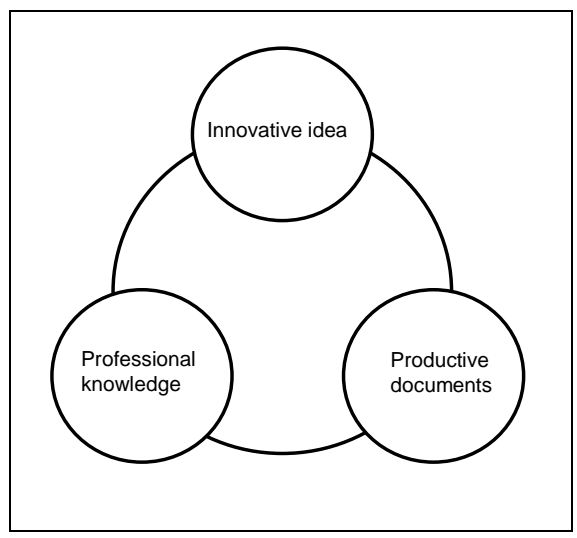

Fig. 1: A wheel diagram.

A diagram of a pentagram for RED was illustrated to clarify the functions constructed by the five concepts, which developed in accordance with the practice of postmodernist fashion in China, and constructed the wholistic structure of the design studio (Figure 2).

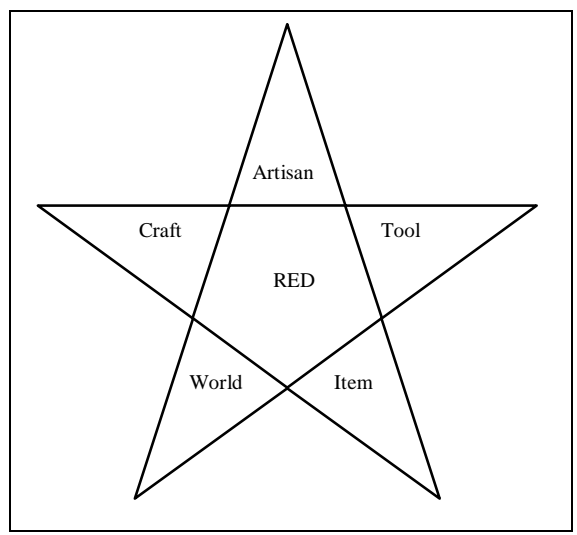

Fig. 2: A diagram of pentagram RED.

\section{References}

[1] D. Roche, The Culture of Clothing: Dress and Fashion in the Ancient Re- 
gime, trans. by J. Birrel, Cambridge University Press, 1994.

[2] E. Paulicelli, Fashion Under Fascism: Beyond the Black Shirt, Berg, Oxford, New York, 2004.

[3] J. Needham, Science and Civilisation in China, Vol. 4: Physical Technology, Part 2: Mechanical Engineering, Cambridge University Press, Cambridge, London, New York, Melbourne, 1965.

[4] J. Wang, G. Taylor, S. Jiang, "A Survey of the Traditions of Postmodernist Design: the Perspective of Personal Interests," International Textile and Apparel Sustainability Conference, Mauritius, 2012.

[5] J. Wu, Chinese Fashion: From Mao to Now, Berg, Oxford, New York, 2009.

[6] L. Ledderose, The Thousand Things: Module and Mass Production in Chinese Art, Princeton University Press, Princeton, New Jersey, 2000.
[7] L. Montgomery, "Fashion and consumer entrepreneurs," China's Creative Industries: Copyright, Social Network Markets and the Business of Culture in A Digital Age, Edward Elgar Publishing, Williston, pp. 75- 93, 2010.

[8] P. Bourdieu, "Haute couture and haute culture," Sociology in Question, P. Bourdieu, ed., Sage Publications, London, Thousand Oaks, New Delhi, pp. 132-138, 1974.

[9] R. Barthes, The Fashion System, trans. by M. Ward, R. Howard, Jonathan Cape, London, 1985.

[10] S. Tsui, China Fashion: Conversations with Designers. Berg, Oxford, New York, 2009.

[11] T. Brown, J. Wyatt, "Design Thinking for Social Innovation," Stanford Social Innovation Review, Winter, pp. 31-35. 2010. 